\title{
CONTAMINAÇÃO POR ENTEROPARASITOS EM VERDURAS DE SUPERMERCADOS E FEIRAS DE UMUARAMA - PR ${ }^{1}$
}

\author{
Kellen Cristina Fernandes ${ }^{2}$ \\ Rodrigo de Almeida ${ }^{2}$ \\ Valdeci Messa ${ }^{3}$ \\ Aristeu Vieira da Silva ${ }^{4 *}$
}

FERNANDES, K. C.; ALMEIDA, R. de; MESSA, V.; SILVA, A. V. da. Contaminação por enteroparasitos em verduras de supermercados e feiras de Umuarama-PR. Arq. Ciênc. Vet. Zool. UNIPAR, Umuarama, v. 17, n. 2, p. 115-119, abr./jun. 2014.

RESUMO: O consumo de verduras in natura pode ser um meio de transmissão de vários parasitos. Este estudo teve como objetivo a avaliação parasitológica de amostras de verduras comercializadas em supermercados e feiras-livres no município de Umuarama - PR. Um total de 48 amostras de alface, 40 de couve, 40 de almeirão e 20 de rúcula foram coletadas, com um total de $20(13,5 \%)$ de positivos para Toxocara $(5,4 \%)$, Ascaris $(5,4 \%)$, Hymenolepis nana $(1,4 \%)$, Entamoeba coli $(0,7 \%)$ e Taenia $(0,7 \%)$.

PALAVRAS-CHAVE: Ascaris. Helmintos. Hortaliças. Protozoários. Taenia. Toxocara.

\section{ENTEROPARASITE CONTAMINATION IN VEGETABLES FROM SUPERMARKETS MARKETS AND STREET MARKETS IN UMUARAMA - PR}

\begin{abstract}
The consumption of fresh vegetables can be a means of transmission of several parasites. This study aims to assess the presence of enteroparasites in samples of vegetables sold in supermarkets and street markets in the city of Umuarama-PR, Brazil. A total of 48 samples of lettuce, 40 samples of cabbage, 40 of curly endive and 20 of rucola were collected, with 20 (13.5\%) being positive, for Toxocara (5.4\%), for Ascaris (5.4\%), for Hymenolepis nana (1.4\%), for Entamoeba coli $(0.7 \%)$ and for Taenia $(0.7 \%)$.
\end{abstract}

KEY-WORDS: Ascaris. Helminths. Vegetable. Protozoa. Taenia. Toxocara.

\section{CONTAMINACIÓN POR ENTEROPARÁSITOS EN VERDURAS DE SUPERMERCADOS Y FERIAS DE UMUARAMA - PR}

RESUMEN: El consumo de verduras in natura puede ser un medio de transmisión de varios parásitos. Este estudio ha tenido como objetivo la evaluación parasitológica de muestras de verduras comercializadas en supermercados y ferias libres en el municipio de Umuarama-PR. Un total de 48 muestras de lechuga, 40 de col, 40 de achicoria y 20 de rúcala, han sido recogidas, con un total de $20(13,5 \%)$ de positivos para Toxocara $(5,4 \%)$, Ascaris $(5,4 \%)$, Hymenolepis nana $(1,4 \%)$, Entamoeba coli $(0,7 \%)$ y Taenia $(0,7 \%)$.

PALABRAS CLAVE: Ascaris. Helmintos. Hortalizas. Protozoarios. Taenia. Toxocara.

Introdução

No Brasil os helmintos intestinais possuem elevada prevalência (AGUIAR-SANTOS et al., 2013). Uma das formas de infecção é o consumo de hortaliças, que apesar de seu valor nutritivo, quando consumidas in natura, podem transmitir micro-organismos patogênicos ao homem. Alguns fatores determinam a distribuição de contaminantes de origem fecal nas hortaliças, como as condições higiênico sanitárias, as práticas de agricultura, o transporte, acondicionamento e comercialização (BARUFFALDI et al., 1984).

Diversos autores brasileiros relatam o encontro de estágios parasitários de helmintos e protozoários contaminando verduras, em taxas que vão de 6,25\% (MESQUITA et al., 1999) a até 100\% das amostras examinadas (SILVESTRE et al., 2009).

Entres as verduras mais frequentemente estudadas para a presença de parasitos, no alface são relatadas taxas de contaminação de $0 \%$ (BARUFFALDI et al.,1984) a até
100\% (SILVESTRE et al., 2009), com mediana de 63\% (BARUFFALDI et al., 1984; OLIVEIRA; GERMANO, 1992a; TAKAYANAGUI et al., 2000; SARAIVA et al., 2005; SOARES; CANTOS, 2006; SILVESTRE et al., 2009; CAVALCANTE; CORREA, 2010; ALVES, CUNHA-NETO e ROSSIGNOLI, 2013). Rúcula (BARUFFALDI et al., 1984; TAKAYANAGUI et al., 2000; SOARES; CANTOS, 2006), escarola (OLIVEIRA; GERMANO, 1992a), agrião (OLIVEIRA; GERMANO, 1992a; TAKAYANAGUI et al., 2000; SOARES; CANTOS, 2006), e almeirão (TAKAYANAGUI et al., 2000) são outras verduras examinadas, com taxas medianas de contaminação de $20 \%, 44 \%, 66 \%$ e $0 \%$, respectivamente.

Os parasitos encontrados em verduras englobam diversas espécies de protozoários e helmintos, sendo os protozoários mais frequentes, com mediana de contaminação de 14\% das amostras (BARUFFALDI et al., 1984; OLIVEIRA; GERMANO, 1992b; TAKAYANAGUI et al., 2000; GUIMARÃES et al., 2003; GARCIA et al., 2004; SANTOS et al.,

DOI: https://doi.org/10.25110/arqvet.v17i2.2014.4929

${ }^{1}$ Entidade financiadora: Universidade Paranaense - UNIPAR - Umuarama - PR;

${ }^{2}$ Farmacêuticos, egressos do Curso de Farmácia da UNIPAR/Umuarama;

${ }^{3}$ Biólogo, Laboratório de Biologia Molecular do Mestrado em Ciência Animal da UNIPAR - Umuarama - PR;

${ }^{4}$ Grupo de Pesquisa em Zoonoses e Saúde Pública, Departamento de Ciências Biológicas, Universidade Estadual de Feira de Santana. Rodovia Transnordestina, s/n - Novo Horizonte - CEP 44.036-900 - Feira de Santana - BA - 75-3161-8314 - aristeuvsilva@uefs.br.* Aristeu Vieira da Silva é bolsista produtividade $\mathrm{CNPq}$ área de Medicina Veterinária, nível 2. 
2009; CAVALCANTE; CORREA, 2010; LOPES et al., 2012; OLIVEIRA et al., (2013), seguidos pelos platelmintos com 11\% de contaminação (OLIVEIRA; GERMANO, 1992a) e nematelmintos com 7\% de mediana de amostras contaminadas (BARUFFALDI et al., 1984; OLIVEIRA; GERMANO, 1992a; TAKAYANAGUI et al., 2000; GUIMARÃES et al., 2003; GARCIA et al., 2004; SANTOS et al., 2009; LOPES et al., 2012; OLIVEIRA et al., 2013).

Entre os nematelmintos, ovos e larvas de ancilostomídeos são os mais frequentemente encontrados, com variação de $8,5 \%$ (TAKAYANAGUI et al., 2000) a até 40\% (SANTOS et al., 2009). É importante registrar a presença de Toxocara, um parasito de origem animal, com taxas de contaminação de $0,1 \%$ (GUIMARÃES et al., 2003) a até 2,5\% (OLIVEIRA; GERMANO, 1992a), e que no ser humano causa síndrome com amplo espectro de apresentações, conhecidas genericamente por larva migrans visceralis.

Baseando-se na análise da literatura, este trabalho teve como objetivo verificar a presença de estágios de enteroparasitos em amostras de alface, rúcula, almeirão e couve comercializadas em supermercados e feiras-livres na cidade de Umuarama, PR.

\section{Material e Métodos}

As amostras foram coletadas em cinco supermercados e três feiras livres da zona urbana do município de Umuarama - PR, identificados por letras do alfabeto. Em cada estabelecimento foram coletadas amostras de alface (Lactuca sativa), rúcula (Eruca vesicaria sativa (Mill) Thell), couve (Brassica oleracea) e almeirão (Chicorium intybus) sendo cada amostra representada por um maço de cada verdura. As amostras foram transportadas em sacos plásticos individuais até o Laboratório de Parasitologia da Universidade Paranaense, Umuarama. Algumas amostras foram analisadas logo após a coleta, enquanto que outras foram armazenadas, por no máximo 24 horas, sob refrigeração.

A análise da presença de estágios parasitários foi realizada segundo o descrito por Takayanagui et al. (2000).
Para cada verdura foi realizada uma única lavagem por enxaguadura, dentro do saco plástico, onde foi adicionado $250 \mathrm{ml}$ de água destilada, agitando-se o mesmo por 30 segundos. A água da lavagem foi deixada em repouso em cálice cônico por 24 horas após filtragem em gaze de oito dobras, e uma gota do sedimento obtido avaliado ao microscópio óptico por exame direto após adição de uma gota de lugol. O reconhecimento dos diferentes parasitos deu-se pelas características morfológicas dos estágios parasitários, segundo o descrito por Neves (2003) e Urquhart et al. (2009).

A associação entre positividade das amostras e o local de coleta - supermercado ou feira - foi avaliada pelo Teste Exato de Fischer, utilizando-se o programa EpiInfo 7 (DEAN et al., 2011).

\section{Resultados}

No município de Umuarama - PR foram coletadas 48 amostras de alface, 40 amostras de almeirão e 40 amostras de couve, em supermercados e feiras. Amostras de rúcula, em número de 20, foram obtidas apenas em supermercados. As amostras foram encontradas em bom estado, porém as de supermercados foram encontradas mais limpas e sem manchas, já algumas amostras de feiras estavam sujas e/ou manchadas.

Estágios parasitários não foram encontrados em nenhuma amostra de couve, mas protozoários e helmintos foram encontrados em 11 (27,5\%) das amostras de almeirão, oito $(16,7 \%)$ das amostras de alface e em três $(15,0 \%)$ das amostras de rúcula. Do total de amostras de verduras examinadas ( $n=148), 20(13,5 \%)$ estavam contaminados por estágios parasitários de helmintos ou protozoários.

Os parasitos mais frequentemente encontrados foram o Toxocara spp e Ascaris lumbricoides, em oito (5,4\%) das amostras examinadas, seguidos de Hymenolepis nana, com duas $(1,4 \%)$ amostras contaminadas, e Entamoeba coli e Taenia, com uma $(0,7 \%)$ amostra com cada um destes parasitos (Tabela 1).

Tabela 1: Número de amostras $(\mathrm{N})$ de verduras, número e porcentagem total de positivos (POS), número e porcentagem total de parasitos encontrados em amostras de alface, rúcula, almeirão e couve, segundo os locais de coleta, Umuarama, 2005.

\begin{tabular}{|c|c|c|c|c|c|c|c|}
\hline \multirow[b]{2}{*}{ Local } & \multirow[b]{2}{*}{$\mathbf{N}$} & \multirow[b]{2}{*}{ POS } & \multicolumn{5}{|c|}{ Estágios parasitários de } \\
\hline & & & E. coli & Taenia & Toxocara & A.lumbr. & H. nana \\
\hline \multicolumn{8}{|c|}{ Supermercado } \\
\hline A & 20 & $8(40,0 \%)$ & $1(5,0 \%)$ & $1(5,0 \%)$ & 0 & $5(25,0 \%)$ & $1(5,0 \%)$ \\
\hline $\mathrm{B}$ & 20 & $0(0,0 \%)$ & 0 & 0 & 0 & 0 & 0 \\
\hline $\mathrm{C}$ & 20 & $5(20,0 \%)$ & 0 & 0 & $5(25,0 \%)$ & 0 & 0 \\
\hline $\mathrm{D}$ & 20 & $2(10,0 \%)$ & 0 & 0 & 0 & $2(10,0 \%)$ & 0 \\
\hline $\mathrm{E}$ & 15 & $1(6,7 \%)$ & 0 & 0 & 0 & $1(6,7 \%)$ & 0 \\
\hline Sub-total & 95 & $16(16,8 \%)$ & $1(1,0 \%)$ & $1(1,0 \%)$ & $5(5,2 \%)$ & $8(8,4 \%)$ & $1(1,0 \%)$ \\
\hline
\end{tabular}

\section{Feiras}

\begin{tabular}{llllllll} 
A & 18 & $3(16,7 \%)$ & 0 & 0 & $3(16,7 \%)$ & 0 & 0 \\
B & 17 & 0 & 0 & 0 & 0 & 0 & 0 \\
C & 18 & $1(5,6 \%)$ & 0 & 0 & 0 & 0 & $1(5,6 \%)$ \\
\hline Sub-total & $\mathbf{5 3}$ & $\mathbf{4 ( 7 , 5 \% )}$ & $\mathbf{0}$ & $\mathbf{0}$ & $\mathbf{3 ( 5 , 7 \% )}$ & - & $\mathbf{1 ( 1 , 9 \% )}$ \\
\hline Total Geral & $\mathbf{1 4 8}$ & $\mathbf{2 0 ( 1 3 , 5 \% )}$ & $\mathbf{1}(\mathbf{0 , 7} \%)$ & $\mathbf{1 ( 0 , 7 \% )}$ & $\mathbf{8 ( 5 , 4 \% )}$ & $\mathbf{8 ( 5 , 4 \% )}$ & $\mathbf{2 ( 1 , 3 \% )}$
\end{tabular}

Obs.: $\mathrm{N}=$ número de amostras examinadas; $\mathrm{POS}=$ número de amostras positivas; E.coli=Entamoeba coli; A.lumbr.=Ascaris lumbricoides; H.nana=Hymnolepis nana. 
A partir das amostras de alface em supermercados obtiveram-se cinco (20\%) amostras positivas e 20 (80\%) negativas, num total de $25(100 \%)$. Já nas feiras, três (13\%) foram positivas e $20(87 \%)$ negativas, num total de $23(100 \%)$ amostras avaliadas. No total geral, computando as amostras coletadas em supermercados e feiras, oito $(17 \%)$ foram positivas, $40(83 \%)$ negativas, totalizando $48(100 \%)$ amostras avaliadas.

Foram coletadas 20 amostras de rúcula em quatro supermercados, sendo que em um dos supermercados, e nas feiras, não foram encontradas amostras desta verdura para coleta. Em um dos três supermercados avaliados, três amostras desta verdura estavam contaminadas por ovos de Toxocara spp.

Ovos ou larvas foram encontrados em 38 (95\%) das amostras de almeirão examinadas, sendo em sua maioria larvas de helmintos de vida livre, encontradas em todos os estabelecimentos estudados, constituindo a maior parte dos resultados positivos $(92,5 \%$ das amostras). Foram encontrados nas amostras coletadas em supermercado, sete (1,75\%) ovos de Ascaris em 25 amostras de almeirão e uma amostra de almeirão $(0,25 \%)$ contendo ovo de Hymnolepis. Já nas amostras coletadas nas feiras foram encontradas três $(0,75 \%)$ amostras com ovos de Toxocara entre as 15 amostras examinadas.

A despeito da razão de chance de encontro de amostras positivas $(n=16 ; 16,8 \%)$ em supermercados ter sido 2,48 vezes maior do que em feiras $(n=4 ; 7,5 \%)$, este resultado não foi significativo.

\section{Discussão}

A frequência de enteroparasitos em amostras de verduras varia nos diversos trabalhos realizados (BARUFFALDI et al., 1984; OLIVEIRA; GERMANO, 1992a; TAKAYANAGUI et al., 2000; SARAIVA et al., 2005; SOARES; CANTOS, 2006; SILVESTRE et al., 2009; CAVALCANTE; CORREA, 2010; ALVES; CUNHA-NETO; ROSSIGNOLI, 2013). Oliveira e Germano (1992a, 1992b) avaliaram 200 amostras, e encontraram $100 \%$ de positividade para algum tipo de parasito, resultado similar ao de Guimarães et al. (2003), que encontraram 100\% das 120 amostras avaliadas positivas para estágios parasitários. Os resultados destes autores contrastam com os obtidos neste trabalho, onde foi encontrado um índice geral de contaminação de $13,5 \%$. Por outro lado, Garcia et al. (2004), examinando verduras obtidas em plantações no município de Umuarama, encontraram uma taxa de 18,8\% de contaminação, semelhante ao encontrado neste trabalho. Já Takayanagui et al. (2001) encontraram uma taxa de contaminação de $33 \%$ entre as 172 amostras de verduras examinadas, o que demonstra que as taxas de contaminação das verduras podem variar de um local para outro, principalmente em função das condições de produção, manipulação e armazenamento das mesmas.

Neste trabalho foi encontrado um total de $16,7 \%$ de amostras de alface positivas, o que se assemelha ao encontrado na pesquisa de Garcia et al. (2004), que encontraram $18,2 \%$ de positivos nas amostras de alface lisa e $8,71 \%$ nas amostras de alface crespa. Estes resultados diferem consideravelmente dos trabalhos de Oliveira e Germano (1992a, 1992b) e Guimarães et al. (2003) onde as taxas de contaminação foram da ordem de $100 \%$ das amostras de alface avaliadas.
O período em que amostras foram coletadas, neste trabalho, foi chuvoso, o que pode ter influenciado no grau de contaminação das amostras, já que estudos demonstraram que os percentuais de contaminação podem estar relacionados com o período de colheita, onde nas épocas chuvosas as hortaliças apresentam valores sensivelmente mais baixos (OLIVEIRA; GERMANO, 1992b).

Poucos trabalhos na literatura reportam a pesquisa de parasitos em amostras de rúcula. Baruffaldi et al. (1984) avaliaram cinco amostras de rúcula, cada uma representada por cinco maços da planta, sendo que $20 \%$ estavam contaminadas por protozoários ciliados, cistos de ameba, ovos de helmintos e ovos de ancilostomídeo. Igualmente, Takayanagui et al. (2001) analisaram dez amostras desta verdura, onde $40 \%$ estavam contaminadas, sem entretanto definir qual o parasito encontrado. Nesta pesquisa o número de amostras de rúcula foi menor que o de alfaces, num total de 20 amostras avaliadas, sendo três (15\%) positivas para ovos de Toxocara, indicando a contaminação com fezes de animais, diferindo do encontrado por outros autores.

Neste trabalho foram encontrados cinco diferentes espécies entre protozoários e helmintos contaminando as amostras de alface, rúcula e almeirão, sendo os parasitos mais frequentes Toxocara e Ascaris, com oito (5,4\%) amostras contaminadas. Takayanagui et al. (2001) também reportam o encontro de Toxocara, indicando a contaminação das verduras com fezes de cães ou gatos. A importância deste parasito ao homem reside no fato de sua forma larvária acarretar manifestações da síndrome de larva migrans visceralis, incluindo graves complicações pulmonares, oculares e neurológicas (MacPHERSON, 2013).

Outros parasitos, como Taenia e Hymenolepis, foram encontrados com frequência de uma ocorrência entre as amostras de alface examinadas. Oliveira e Germano (1992a) assinalam o encontro de ovos de Taenia em 2\% das amostras de alface lisa examinadas. É importante destacar que a ingestão de ovos deste cestódeo, caso sejam da espécie Taenia solium, podem levar a ocorrência de cisticercose humana, doença que pode gerar graves sequelas neurológicas (DHAMA et al., 2013).

Oliveira e Germano (1992a), Takayanagui et al.(2001) e Garcia et al. (2004) apontam o encontro de $A s$ caris em $8 \%, 13,1 \%$ e $9,7 \%$, respectivamente, das amostras examinadas. Este parasito, além de ser eliminado pelo hospedeiro em grande quantidade, apresenta resistência ambiental elevada, são exclusivos do homem, e seu encontro fortalece a hipótese de ocorrência de contaminação por fezes humanas.

Oliveira e Germano (1992b) encontraram Entamoeba coli em 10\% das amostras de alface examinadas, enquanto que neste trabalho este protozoário foi encontrado em uma amostra, ou seja, 4\% das alfaces examinadas. Embora não seja considerado patogênico, este protozoário apresenta grande valor como indicador de contaminação fecal de origem humana nas verduras. Deve-se ressaltar, entretanto, que a metodologia utilizada neste experimento não foi a mais adequada para a detecção de protozoários, desta maneira, outras espécies, como Entamoeba hystolitica, Giardia intestinalis e Cryptosporidium, relatados por outros autores, podem ter sido subdiagnosticados.

Oliveira e Germano (1992a) encontraram duas $(4,0 \%)$ de 50 amostras de alface crespa, quatro $(8,0 \%)$ de 50 amostras de escarola e sete $(14,0 \%)$ de 50 amostras de agrião, contaminadas com ovos de Hymenolepis, enquanto 
que Takayanagui et al. (2000) encontraram duas $(0,7 \%)$ das 26 hortas contaminadas com este parasito em amostras de alface. Neste trabalho foi encontrada uma $(2,5 \%)$ amostra contaminada com ovos de Hymnolepis em amostras de almeirão, o que difere substancialmente da literatura.

O Hymnolepis pode ocasionar infecções humanas com o aparecimento de perturbações devido ao número de vermes albergados. Nas crianças pode ocorrer agitação, insônia, irritabilidade, diarréia, dor abdominal, podendo ocorrer sintomas nervosos como ataques epiléticos, cianose, perda da consciência e convulsões (RAETHER, HÄNEL, 2003).

O não encontro de parasitos na couve pode ter sido pelas ótimas condições destas verduras encontradas nos locais de venda. Em todos os locais, as verduras estavam lavadas e em ótimo estado. Por outro lado, as folhas da couve não estão normalmente em contato com a terra, o que de certa forma pode explicar o não encontro de parasitos. Oliveira e Germano (1992a) relatam que o tipo de folha das diferentes espécies de verdura pode influenciar na fixação de cistos e outras estruturas parasitárias, o que também pode estar relacionado ao não encontro de parasitos nas amostras desta verdura

Com relação à diferença de contaminação em verduras obtidas de supermercado e feiras-livres, neste trabalho não foi encontrada diferença significativa entre os locais de coleta de amostras. Takayanagui et al. (2001), examinando 16 amostras obtidas em feiras-livres e 38 amostras de supermercados, encontraram respectivamente sete $(13 \%)$ e nove (17\%) positivos, entretanto, sem verificar diferença significativa entre as origens das verduras, o que também foi demonstrado por Guimarães et al. (2003). A despeito da qualidade sensorial das verduras nos supermercados ter sido superior à das feiras, verificou-se uma maior contaminação nas amostras coletadas em supermercados.

Dos diversos trabalhos encontrados na literatura nacional e internacional, e dos resultados obtidos nesta pesquisa, depreende-se a importância das verduras na transmissão de enteroparasitos, e a necessidade constante de atividades de vigilância que permitam o monitoramento da contaminação destes vegetais, fundamentando a tomada de decisões em segurança alimentar.

As doenças veiculadas por alimentos são resultantes predominantemente do ciclo de contaminação, e seu controle tem recebido atenção cada vez maior em todo o mundo. A desinfecção destas verduras pode apresentar relevância considerável no sentido de minimizar os riscos de transmissão de enteroparasitoses. Uma vez que a lavagem simples não reduz a contaminação, um método simples e eficaz consiste na imersão das folhas em água aquecida a $60^{\circ} \mathrm{C}$, por dez minutos. Este procedimento deve ser especialmente considerado na formulação de programas educativos direcionados à população consumidora desses alimentos (BARRUFALDI et al., 1984).

\section{Conclusão}

Existe contaminação por enteroparasitos em amostras de alface, rúcula e almeirão comercializadas em supermercados e feiras-livres no município de Umuarama, PR, entretanto sem associação entre local de coleta de amostras e frequência de contaminação.

\section{Referências}

AGUIAR-SANTOS, A. M. et al. Epidemiological assessment of neglected diseases in children: lymphatic filariasis and soil-transmitted heminthiasis. Journal of Pediatrics, Rio de Janeiro, v. 89, n. 3, p. 250-255, 2013.

ALVES, A. S.; CUNHA-NETO, A.; ROSSIGNOLI, P. A. Parasitos em alface-crespa (Lactuca sativa L.), de plantio convencional, comercializada em supermercados de Cuiabá, Mato Grosso, Brasil. Revista de Patologia Tropical, Uberlândia, v. 42, n. 2, p. 217-229, 2013.

BARUFFALDI, R. et al. Tratamento químico de hortaliças poluídas. Revista de Saúde Pública, São Paulo, v. 18, n. 3, p. $225-34,1984$.

CAVALCANTE, M. S.; CORREA, E. A. Avaliação parasitológica e condições higiênico-sanitárias de hortaliças comercializadas na cidade de Cruzeiro do Sul, Acre, Brasil. PrimeiraVersão, Porto Velho, v. 28, n. 262, p. 2-11, 2010.

DEAN, A. G. et al. Epi Info ${ }^{\text {TM }}$, a database and statistics program for public health professionals. Atlanta: CDC, 2011.

DHAMA, K. et al. Food-borne pathogens of animal origin - Diagnosis, prevention, control and their zoonotic significance: a review. Pakistane Journal of Biological Science, Faisalabad, v. 16, n. 20, p. 1076-1085, 2013.

GARCIA, J. L. et al. Ocorrência de helmintos e protozoários e hortaliças produzidas em UmuaramaPR. Arquivos de Ciências Veterinárias e Zoologia da UNIPAR, Umuarama, v. 7, n. 1, p. 37-41, 2004.

GUIMARÃES, A. M. et al. Frequência de enteroparasitos em amostras de alface comercializadas em Lavras, Minas Gerais. Revista da Sociedade Brasileira de Medicina Tropical, Uberaba, v. 36, n. 5, p. 621-623, 2003

LOPES, F. K. et al. Presença de enteroparasitos e ensaio de sanitização de hortaliças distribuídas em unidades de ensino e comércios da zona leste do município de Porto Velho. In: SEMINÁRIO DE INICIAÇÃO CIENTÍFICA, 2., 2012, Colorado do Oeste. Resumos... Colorado do Oeste: DEPIPG, 2012. p. 1-3.

MacPHERSON, C. N. The epidemiology and public importance of toxocariasis: a zoonosis of global importance. International Journal for Parasitology, Oxford, v. 43, n. 12-13, p. 999-1008, 2013.

MESQUITA, V. C. L. et al. Intestinal parasites contaminationfrom vegetables comercialized in Niterói and Rio de Janeiro cities, Brazil. Revista da Sociedade Brasileira de Medicina Tropical, Uberaba, v. 32, n. 4, p. 363-366, 1999.

NEVES, D. P. Parasitologia Dinâmica. São Paulo: Atheneu, 2003. 608 p.

OLIVEIRA, C. A. F. O.; GERMANO, P. M. L. Estudo da 
ocorrência de enteroparasitos de hortaliças comercializadas na região metropolitana de São Paulo - SP, Brasil. I -Pesquisa de helmintos. Revista de Saúde Pública, São Paulo, v. 26, n. 4, p. 283-289, 1992a.

OLIVEIRA, C. A. F. O.; GERMANO, P. M. L. Estudo da ocorrência de enteroparasitos de hortaliças comercializadas na região metropolitana de São Paulo - SP, Brasil. II Pesquisa de protozoários intestinais. Revista de Saúde Pública, São Paulo, v. 26, n. 5, p. 332-335, 1992 b.

OLIVEIRA, S. R. P. et al. Prevalência de parasitos em alface em estabelecimentos comerciais na cidade de Bebedouro, São Paulo. Revista Saúde, Goiânia, v. 7, n. 1-2, p. 5-10, 2013.

RAETHER, W.; HÄNEL, H. Epidemiology, clinical manifestations and diagnosis of zoonotic cestode infections: an update. Parasitology Research, Berlim, v. 91, n. 5, p. 412-438, 2003

SANTOS, N. M. et al. Avaliação parasitological de hortaliças comercializadas em supermercados e feiras livres no município de Salvador, BA. Revista de Ciências Médicas e Biológicas, Salvador, v. 8, n. 2, p. 146-152, 2009 .

SARAIVA, N. et al. Incidência da contaminação parasitária em alfaces nos municípios de Araraquara (SP) e São Carlos (SP). Revista UNIARA, Araras, v. 1, n. 16, p. 213-218, 2005.

SILVESTRE, C. et al. Avaliação microbiológica e parasitológica de alfaces (Lactuca sativa L.) comercializadas em Criciúma, SC. In: SALÃO DE INICIAÇÃO CIENTÍFICA DA PUCRS, 31., 2009, Porto Alegre. Anais... Porto Alegre: EDIPUCRS, 2009. p. 949951.

SOARES, B.; CANTOS, G. A. Detecção de estruturas parasitárias em hortaliças comercializadas na cidade de Florianópolis, SC, Brasil. Revista Brasileira de Ciências Farmacêuticas, São Paulo, v. 42, n. 3, p. 455-460, 2006.

TAKAYANAGUI, O. M. et al. Fiscalização de hortas produtoras de verduras do município de Ribeirão Preto, SP. Revista da Sociedade Brasileira de Medicina Tropical, Uberaba, v. 33, n. 2, p. 169-174, 2000.

TAKAYANAGUI, O. M. et al. Fiscalização de verduras comercializadas no município de Ribeirão Preto, SP. Revista da Sociedade Brasileira de Medicina Tropical, Uberaba, v.34, n.1, p.37-41, 2001.

URQUHART, G. M. et al. Parasitologia Veterinária. 3. ed. Rio de Janeiro: Guanabara Koogan. 2009. 285 p. 